\title{
The effect of the urban wastewater treatment ratio on agricultural water productivity: based on provincial data of China in 2004-2010
}

\author{
Yuanhong Tian ${ }^{1,3} \cdot$ Jinfeng Ding ${ }^{2,4} \cdot$ Dajian Zhu $^{2,3} \cdot$ Nicholas Morris $^{4,5}$
}

Received: 28 December 2017 / Accepted: 3 August 2018 / Published online: 14 August 2018

(c) The Author(s) 2018

\begin{abstract}
China's urbanization has always required the support of rural areas. By 2014, urban wastewater pollution had become a serious problem in China and this drew the public's attention to the urban water environment. As a result, the government now requires a new type of urbanization, with simultaneous development of high-quality rural areas. Improving the economic, social and environmental influence of urban development on rural areas helps to improve urbanization and make rural areas more sustainable. This article focuses on a particular question: Have urban wastewater emissions affected the efficiency of agricultural water use? Using provincial panel data for 2004-2010, we analyze how the increase in the urban wastewater treatment ratio has changed China's agricultural water productivity. The effect is shown to be prominent, irrespective of whether the urbanization ratio is high or low. This effect is most significant when the urbanization ratio is highest or when society pays more attention to urban environmental governance. The influence has regional heterogeneity and is also affected by various other policy settings. The results provide helpful guidance for cities as they focus on rural impacts as part of the new type of urbanization policies.
\end{abstract}

Keywords Urban wastewater treatment ratio $\cdot$ Agricultural water productivity $\cdot$ Urbanization $\cdot$ Agricultural water

Jinfeng Ding

dingjinfeng2016@163.com

Yuanhong Tian

tianyuanhong@hotmail.com

Dajian Zhu

dajianzhu@263.net

Nicholas Morris

n.morris@atasia.org

1 School of Social Science, Shanghai University of Engineering, Shanghai 201620, China

2 School of Economics and Management, Tongji University, Shanghai 200092, China

3 Institution of Sustainability Development and Management, Tongji University, Shanghai 200092, China

4 School of Teaching and Research, China Executive Leadership Academy Pudong, Shanghai 201204, China

5 School of Law, University of New South Wales, Sydney 2052, Australia

\section{Introduction}

An amended Environmental Protection Law took effect in China on January 1, 2015. This law provided clear guidance on daily fines, seizure of pollution sources and information disclosure. New daily fines can now be as high as thirty times the previous fine. This level of fine shows the central government's determination to fight water pollution, in response to the severe water pollution in China which existed at the time of its enactment.

In April 2014, water pollution crises in big cities such as Lanzhou, Wuhan and Jinjiang occurred one after another, which focused the public's attention on urban water safety. China has suffered from severe water pollution since at least 2004. Serious water pollution incidents had been recorded at an average of 1700 per year between 2004 and 2014. These incidents highlighted the accumulated water pollution and the need to attend to water environmental governance as a matter of utmost urgency.

Besides the amended Environmental Protection Law, National Model Town Planning was announced in 2014. This set targets of raising the urban wastewater treatment ratio from $87.3 \%$ in 2012 to $95 \%$ in 2020 , in order to

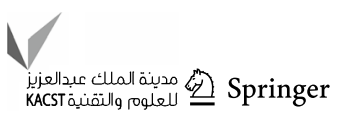


alleviate urban water pollution's negative effect both on the city itself and on the rural area around it. Laws and policies related to wastewater pollution are becoming more refined, but the implementation of these policies still needs improvement. One reason for this inefficiency is that quantification of economic loss, environmental damage and hazards to society caused by urban wastewater pollution is still limited. This makes China's water pollution hard to contain.

In order to redress this problem, this article analyzes the effect of urban wastewater quantitatively and focuses particularly on the effect on the product efficiency of agricultural water. Such quantification sheds light on how to balance the development of both urban and rural areas during urbanization in China. The National Model for Town Planning declares that ensuring quality urbanization is the way to achieve simultaneous development of both rural and urban areas. Analyzing urbanization's environmental effect on agriculture is helpful in identifying potential problems in the process.

Existing research on the effect of urban wastewater emissions on agricultural water productivity has mainly discussed the question qualitatively, with limited attention to quantitative evidence. Quantifying urban wastewater's effect on agricultural productivity is important in understanding how urban areas can re-feed rural areas and thus improve the sustainability of the agricultural sector.

\section{Related studies and hypothesis}

\section{Urban wastewater treatment's effect}

Existing research related to urban wastewater's effect on agricultural productivity can be divided into two parts: research focused within China and international evidence. Some international literature discusses the effect of pollution on agricultural productivity caused by urbanization from an historical perspective. In order to provide enough jobs for urban labor, it was necessary to develop urban industrial and service industries. Upscale service industries such as consulting, finance and banking require highly educated labor, while lower service industries such as housekeeping, tourism and retail require citizens to have high-consumption capability. Developing countries do not have much high-quality laborer or many citizens with high-consumption capability. They have to start from industrialization, which often implies significant pollution. While communities without factories only generate limited pollution, power stations, raw material processing, chemical plants and waste treatment generate substantial pollution (Forrester 1971). Untreated wastewater is usually emitted to rural areas nearby, and some is used for irrigation. Whether it is proper to use the grain irrigated by reclaimed water has generated controversy.
There is also some evidence that reclaimed water decreases agricultural water's efficiency (Varis and Vakkilainen 2001).

Research within China has mainly illustrated urban wastewater's effect on agricultural water's productivity from an environmental science aspect. Urban wastewater has abundant organic pollutants such as N, P, K, bacterium, parasites and viruses, which are the main source of urban water pollution. After treatment, wastewater consists of two parts: one is water, the other is sludge. Treated wastewater can be emitted directly or can be used as reclaimed water. Sludge contains parasite ova, pathogenic microorganisms, and heavy metals, and creates secondary pollution if it is not properly disposed. Both the polluted water and sludge can be harmful to water and soil if emitted or recycled without fulfilling environmental standards.

China has used reclaimed water for agricultural irrigation ever since the Sixth National Plan. During that period, Qingdao and Dalian were chosen as sites for urban reclaimed water used for agriculture irrigation pilots. In 2008, there was 16.6 billion $\mathrm{m}^{3}$ of reclaimed water, comprising $8 \%$ of total urban wastewater emissions. Of this, 4.8 billion $\mathrm{m}^{3}$ reclaimed water was used for agricultural irrigation, some $28.9 \%$ of the total amount. Although Reuse of Urban Recycling Water-Quality of Farmland Irrigation Water and other related rules set standards for urban recycling water used in agricultural irrigation, the recycled water still had a negative effect on agriculture production. For instance, urban recycled water was found to contain hazardous substances that stick on plant surfaces, to cause pollution to rhizome, stems and leaves of vegetables, melons and fruits, and to decrease crop quantity and yield through effects on growth in different periods (Shi et al. 2008).

Even reclaimed water that reaches national standards can have a negative effect on agricultural output, and there is no doubt how harmful the reclaimed water that does not reach the national standards is. Some rural areas use urban untreated wastewater directly to irrigation crops because of water scarcity (Wang 2007). Untreated water or simply treated water can also cause organic pollution to the soil and hence decrease crop growth and quantity. Organic pollution may be leached into groundwater if the irrigation process is not undertaken carefully.

Although the existing literature, both in China and internationally, is limited, it provides sufficient evidence for us to hypothesis that China's urban wastewater treatment processes are likely to affect agricultural water productivity.

\section{Spatial heterogeneity of the urban wastewater treatment ratio's effect}

China's wastewater treatment started comparatively late, and the related financing and operating systems remain inadequate (Tian et al. 2017). Many cities did not include 
wastewater treatment in the initial city plans. The wastewater collection pipe networks were not included in city construction systems, so that it is hard to collect wastewater, and much wastewater therefore cannot be treated under centralized processing. Second, building and operation of wastewater treatment plants requires the government's substantial funding, which many municipal authorities cannot afford. Third, the wastewater charging system still needs to be improved. Some metropolitan authorities do not have a formal way to collect wastewater treatment fees. If a fee is collected, it is sometimes not allocated to the wastewater treatment plants, which causes difficulties with financing and operations. For the reasons listed above, some cities (especially cities in western China) do not have enough wastewater treatment plants or cannot afford the plants' operation even when they have built the plants (Zhou and Huang 2007).

A second hypothesis we explore in this article is that the urban wastewater treatment ratio's effect on agricultural productivity has spatial heterogeneity. In particular, the same urban wastewater treatment ratio has a different effect at different levels of urbanization.

\section{Model establishment}

\section{Characteristics of urban wastewater treatment and agricultural water productivity}

People moving into urban areas are challenges for municipalities' public service capability. In the period we are examining, urban wastewater emission increased from $2.61 \times 10^{11} \mathrm{~m}^{3}$ in 2004 to $3.80 \times 10^{11} \mathrm{~m}^{3}$ in 2010 , a rise of some $45.60 \%$. Although the urban municipalities' public service capability increased in that period, and the wastewater treatment ratio increased from $45.7 \%$ in 2004 to $82.3 \%$ in
2010, there was still 8 billion $\mathrm{m}^{3}$ wastewater emitted into rural areas from urban areas without any treatment, some $20 \%$ of the total emissions.

China's agriculture sector consumes over $60 \%$ of the total water supply, while it produces only $10 \%$ of the total GDP (Tian et al. 2017). So it is facing pressure both to decrease agriculture water quantity used while simultaneously increasing economic productivity. From 2004 to 2010, China's agricultural water share decreased gradually from 64.52 to $61.65 \%$. In 2010 , the agriculture sector consumed $3.69 \times 10^{12} \mathrm{~m}^{3}$ of water.

Meanwhile, the national agricultural economic output also increased substantially. Agriculture water productivity increased from 5.06 to $10.99 \mathrm{RMB} / \mathrm{m}^{3}$, although the improvement was variable across provinces. In advanced regions such as North China, despite water scarcity, accumulated agriculture planting experience has led to considerable improvement, with the result that water productivity in these regions is now much higher than in less developed regions such as Tibet, Qinghai and Ningxia. Some rainfallabundant regions in south China, such as Chongqing, Hunan and Sichuan, have also seen significant improvements.

Figure 1 charts the relationship between the urban wastewater treatment ratio and China's agriculture water productivity in the period 2004-2011. It can be seen that both the urban wastewater treatment ratio and agriculture water productivity have risen during the period. Using panel data for 30 provinces' panel data, we have established an economic model and analyzed the relationship between the wastewater treatment ratio and China's agricultural water productivity.

\section{Control variables}

Agriculture water productivity was computed as agricultural production divided by agriculture water consumption. As independent variables, we explore factors which may influence agricultural production and agricultural water
Fig. 1 Relationship between wastewater treatment ratio and agricultural water productivity Data source: China Statistics, China Tertiary Statistics (2004-2011)

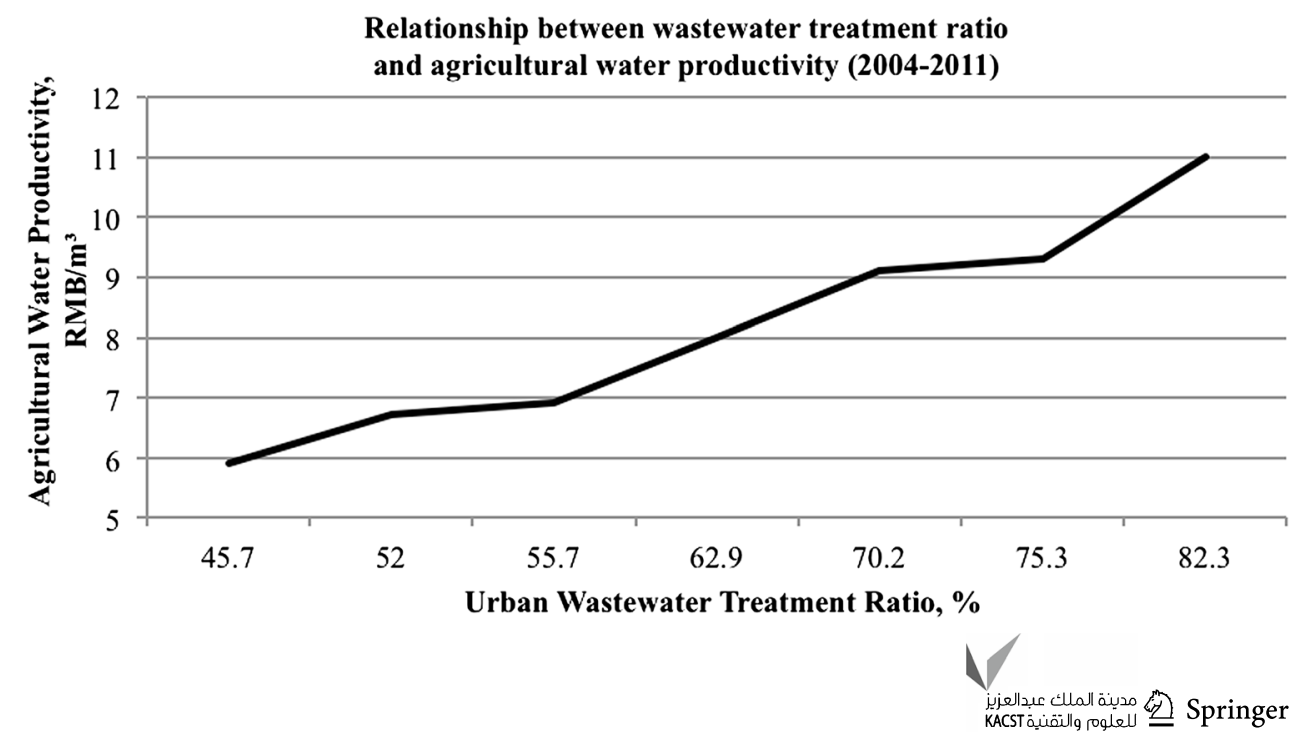


consumption. Ecological economics provides an equation for the growth of the economy as $Q=f(K, L, N)$, where $Q$, $K, L$ and $N$ stand for economic output, capital input, labor force and natural resources. The chosen variables which may influence agriculture can be sorted into these three latter categories, as shown in Table 1.

Potential dependant capital variables are:

1. Industrialization: Manufacturing industry output has overtaken agricultural output to become the main part of the domestic economy (Zhang and Jin 2009). We use an industry output ratio, as a proportion of the total economy, to measure industrialization.

2. Agricultural fixed investment: This includes investment in agriculture manufacture, refining and revitalization, in real terms, to reflect agricultural hydrology investment which increases agricultural water productivity.

3. Agricultural CPI: High water prices will increase irrigation efficiency, as farmers (especially farmers in North China in the lowest income groups) are very sensitive to the water price (Webber et al. 2008). Because of this, the government only charges them a nominal price, in case the farmers give up growing crops, and this in turn threatens food safety (Nickum 1998). Water prices vary from one village to another, or may only be charged in specific crop planting areas, which means it is hard to estimate the average provincial water price directly. Agricultural CPI is an objective reflection of the cost of crop production and reflects structural changes. Therefore, we use agricultural CPI to represent the cost of crop production.

4. Food crop output per person: Agriculture uses over $60 \%$ of national water consumption, and $40 \%$ of agricultural water consumption is taken by crop production; hence, it is an important indicator of fluctuations in both agricultural output and water use.

5. Agriculture power consumption: Mechanization is one of the six main factors which determine agriculture water consumption (Rezadoost and Allahyari 2014). Agricultural mechanization means using tractors, planters, reapers, dynamic drainage and irrigation machines, and automobiles to do land trill, seed, harvest, irrigate, field management, transportation. It is hard to measure agricultural mechanization directly, but agricultural power consumption can be used as a proxy to reflect the degree of mechanization.

6. Fertilizer inputs: In 1981-2007, fertilizer has been shown to have a positive effect on China's agricultural output (Zhang and Zhang 2010). Research in other countries also demonstrates that fertilizer use can promote economic output (Zhao and Li 2009). This article thus uses fertilizer inputs as a control variable.

7. Pesticide: Pesticide use can increase agricultural efficiency, but may also decrease it because of the pollution caused by pesticides (Li et al. 2012).

From the human resource aspect, potential dependant variables are: population, urbanization and the extent of compulsory education. Population is one of the several factors which influence agricultural water consumption listed by IWMI (2013). Population fluctuations may also influence food production, which causes these two factors have potential collinearity. After performing a collinearity test, we used food production per person to eliminate collinearity.

It is widely recognized that urbanization has a direct negative effect on agriculture production, as the land used for urban expansion replaces farming land, rural labor moves to towns, policymakers give preference to investment in urban public facilities and provide subsidies, etc., to cities. The urban population increase thereby forces agriculture to transit to land with lower productivity, and decreases the land available for farming. The lower-quality land may need additional irrigation to offset an inferior environment. Urban industry and domestic water consumption will rise, which may crowd out supply to agriculture (Shen and Liu 2008).

However, urbanization can also have a positive influence on agricultural production. Urbanization improves living standards and may generate surplus capital, part of which is invested into agricultural production, to buy advanced irrigation facilities and increase agricultural water efficiency (Forrester 1971). In addition, cities provide markets for agriculture production, where farmers can supply
Table 1 Control variables for China agricultural water productivity model

\begin{tabular}{lll}
\hline Capital & Human resource & Natural capital \\
\hline (1) Industrialization & (1) Population & (1) Temperature \\
(2) Fixed assets used in agriculture & (2) Urbanization & (2) Rainfall \\
(3) Agricultural CPI & (3) The compulsory education & (3) Affected irrigation land \\
rate in rural areas & \\
(4) Food crop output per person & & \\
(5) Agricultural power consumption & & \\
(6) Pesticides & & \\
(7) Fertilizer & & \\
\hline
\end{tabular}


enterprises with various products and services. Globalization means that agriculture production in different countries is involved in the same world economic system. Agriculture water resources can thus flow between different countries through trading. So a city's urbanization may influence another place's agriculture water usage far away (Tian et al. 2013). As a result of all these factors, urbanization affects agricultural water productivity in many ways, both positive and negative. Urbanization is therefore an important control variable.

Rezadoost and Allahyari research (2014) shows that planting knowledge accessibility will influence agricultural water usage. Knox notes that scientists, government and farmers have different opinions on water efficiency. Farmers see water efficiency as using water to maximize their income, no matter how much water they consume (Knox et al. 2012). Farmer's education can be effective in encouraging them to master planting knowledge and water-saving techniques. In China, farmers' average education level is 7.3 years, lower than compulsory education of 9 years, and this is also used as a control variable.

Potential other control variables which influence agriculture water productivity are: temperature, rainfall and availability of irrigation land. Temperature and rainfall represent climate change, while according to Alex's research more than $30 \%$ of China's farmland needs irrigation, and much of which is in the main food production areas (Thomas 2008).

\section{Data sources}

Due to data constraints, we use data for 30 provincial municipals, for the period 2004-2010, a sample size of 210 province/year data points. Tibet's wastewater treatment ratio data are not available, nor are data prior to 2004 .

Urbanization, agricultural GDP, agricultural water consumption, agricultural power consumption, population and effective irrigation land data were sourced from China Statistics Yearbook, 2005-2011. To eliminate the effect of inflation, agricultural GDP after 2004 was divided by the accumulated CPI, taking 2004 as the base year. Data for agricultural fixed investment, fertilizer and pesticide were sourced from China Rural Statistics Yearbook, 2005-2011. Agricultural capital goods CPI, food production, rural labor, arable land, temperature and rainfall data came from Provincial Statistics Yearbook 2005-2011. Data on farmers who have senior and junior middle school education divided by the number of rural laborers were sourced from China Social Statistics Yearbook 2005-2011, China Population and Employment Statistics Yearbook 2005-2011, and Statistics Yearbook for each province 2005-2011. The urban wastewater treatment ratio came from Statistics Yearbook of each province 2005-2010.

\section{Model testing and results}

\section{Model testing}

1. Correlation Test. In order to determine whether the independent variables had multi-collinearity, a VIF test was conducted after all the variables had been standardized. Fertilizer and crop production's VIF were 13.09 and 10.73 , respectively. Population, irrigation land area and pesticide's VIF were 9.24, 8.19 and 5.45, respectively. Other variables' VIF were less than 5.

Although some studies accept variables if their VIF is less than 10, we narrowed the VIF range to less than 6, keeping variables where the VIF was less than 6 , and altering variables where the VIF was more than 6 to alleviate the effect of multi-collinearity. Fertilizer and pesticide were divided by arable land area to get fertilizer per land and pesticide per land, respectively. Food production was divided by population to get food output per person. After these adjustments, we were left with 13 independent variables which, except temperature, all passed the strict VIF test. The VIF test results are summarized in Table 2:

2. Stationarity test. We used a stationarity test to determine whether these variables had zero means after their intercepts and time trends are excluded, which is also

\begin{tabular}{llll}
\hline Independent variables & VIF & Independent variables & VIF \\
\hline Temperature & 5.3400 & Urbanization ratio & 2.6100 \\
Fertilizer per arable land & 4.7000 & Agriculture power consumption & 2.0800 \\
Effective irrigation land & 4.0100 & Urban wastewater treatment ratio & 1.8900 \\
Pesticide per arable land & 3.9900 & Industrialization ratio & 1.8800 \\
Rainfall & 3.4400 & The popularization rate of compulsory & 1.8300 \\
& & education & \\
Agriculture investment in fixed asset & 3.2100 & Agriculture capital good price index & 1.0700 \\
Food output per capita & 2.6700 & & \\
\hline
\end{tabular}


called a 'unit roots test.' Here are two stationarity test procedures, the LLC test and the IPS test. LLC's null hypothesis is that there is a unique unit root, and IPS's null hypothesis is that there are different unit roots. When both of these null hypotheses cannot be rejected, this term's residual is related to last term's, there is a unit root, which means the panel data is stationary; otherwise, it is not.

The stationarity test results are shown in Table 3, 6 of the variables are zero-order stationary and the other 8 variables have unit roots. These 8 variables also passed the stationarity test after the first-order difference, so they were integrated in one order. As the urban wastewater treatment ratio is one of these 8 variables, we kept them and abandoned those 6 variables which were zero-order stationary, employing a cointegration test later.

3. Co-integration test. Variables which have a unit root, although they are not stationary themselves, but where their linear combination can have equilibrium relationship with the dependent variable in the long run, are acceptable components of a reasonable regression. We employed Kao and Pedroni co-integration tests to estimate whether those 8 variables selected in the previous chapter are co-integrated.

The result shows 5 of those 8 variables were co-integrated with the dependent variable. They are urban wastewater treatment ratio, urbanization ratio, agriculture investment in fixed asset and the popularization rate of compulsory education.

The co-integration test results between these 5 variables' combination and the dependent variable were as follows: the Kao test result was 0.0013 , which rejected the null hypothesis at the 0.05 test level. Pedroni within-group PP and ADF test results were 0.0000 and 0.0000 , while PP between groups PP and ADF results were also 0.0000 and 0.0000 . Both of them rejected the null hypothesis that these variables are not co-integrated. These five dependent variables are thus co-integrated with the dependent variable.
The co-integration relationship also avoids potentially endogenous effects on the model. When the variables are random walk ones but are co-integrated, then the model consisting of these variables can generate consistent OLS regression results (Huang and Shu 2010). Therefore, there is no need to employ an endogeneity test on this model.

Another three variables, industrialization ratio, temperature and pesticide per land, failed to pass the co-integration test, which means their combinations do not have a stationary relationship with the dependent variable and must be excluded by our model; otherwise, there would be spurious regression. We therefore analyzed the urban wastewater treatment ratio's effect on agricultural water productivity under the circumstance of controlling for the other four variables which passed the co-integration test: urbanization, effective irrigation land, agriculture investment in fixed asset and the popularization rate of compulsory education.

\section{Model summary and test results}

1. Model summary and variables descriptive statistics. First, a Hausman test was employed to determine whether a fixed-effect test or random-effect test should be used. The P value of the Hausman test is zero, which means the null hypothesis that the individual factors are not related to provincial variations is rejected. Therefore, we chose a random-effect panel data model, as follows:

$y_{i t}=\alpha+\sum_{i=1}^{n} \beta_{i} x_{i t}+\beta_{j} f e_{j}+\varepsilon_{i t}$

where $y_{i t}$ is the municipal province. $i$ is agricultural water productivity in year $t . x_{i t}$ is municipal province $i$ 's independent variables in year $t . f e_{i}$ is a dummy variable depending on whether they are in the northern or southern region. $\beta_{j}$ is 0 when the province is in southern China and 1 when it is in the northern part. $\alpha$ is the intercept of the regression equation. $\beta_{i}$ is the correlation

Table 3 Stationary test result

\begin{tabular}{|c|c|c|c|c|c|}
\hline Variables & LLC & IPS & Variables & LLC & IPS \\
\hline Agriculture water productivity & 0.8573 & 0 & Agriculture investment in fixed asset & 0.2775 & 0.9220 \\
\hline Urban wastewater treatment ratio & 0 & 0.7880 & The popularization rate of compulsory education & 0.0017 & 0.0120 \\
\hline Urbanization ratio & 1 & 0.9880 & Agriculture power consumption & 0 & 0 \\
\hline Industrialization ratio & 0.4205 & 1 & Food output per capita & 0 & 0 \\
\hline Effective irrigation land & 1 & 1 & Rainfall & 0 & 0 \\
\hline Temperature & 1 & 0.0060 & Agriculture capital good price index & 0 & 0 \\
\hline Pesticide per arable land & 0 & 0.7750 & Fertilizer per arable land & 0 & 0.0010 \\
\hline
\end{tabular}


coefficient between the independent variables and agricultural water productivity. $\varepsilon_{i t}$ is the estimation error.

Statistic descriptions of variables after being standardized in this model are listed in Table 4.

2. Primary test result. Comparing the result of model 1 with the result of model 2 , when urbanization is controlled in model 2, the urban wastewater treatment ratio's influence decreases, and adjusted $R^{2}$ increases slightly, which means urbanization does have an effect on the dependent variable. If urbanization is not considered, the urban wastewater treatment ratio's influence might be slightly over-estimated. Comparing the result of model 3 with the result of model 2, when the urban wastewater treatment ratio is considered, urbanization's influence on the dependent variable turns out to be not significant, and the adjusted $R^{2}$ increases to 0.0815 , the growth rate is $11.82 \%$. This means that the wastewater treatment ratio's increase is the more important reason for changes in agricultural water productivity (Table 5).

3. Regional heterogeneity. The previous results show that when the urbanization ratio is taken into consideration, urban wastewater treatment ratio's effect on agriculture water productivity falls slightly. High urbanization ratio regions are relatively more developed, with higher environmental protection awareness. Thus, these regions have lower rates of urban wastewater discharged into rural areas nearby and thus threaten agricultural water safety less. Therefore, we explored an interaction item between the urbanization ratio and the urban wastewater treatment ratio to test regional heterogeneity.

To test the hypothesis of regional heterogeneity, we created two dummy variables, a low urbanization ratio and a high urbanization ratio based on the $10 \%, 50 \%$ and $90 \%$ quantiles. Taking the $50 \%$ quantile as an example, when the urbanization ratio is less than or equal to $44.05 \%$, the high urbanization ratio dummy variable is zero, and the low urbanization ratio dummy variable is 1 . When the urbanization ratio is more than $44.05 \%$, the high urbanization ratio dummy variable is 1 , and low urbanization ratio dummy variable is zero. The results are shown in Table 6:

On the $50 \%$ and $90 \%$ quantiles, the high urbanization ratio regions have larger effect on the independent variable than the lower ones. On the 50\% quantiles, this differentiation reaches $15 \%$. That means when urban wastewater treatment ratio rises by $1 \%$, high urbanization ratio regions stimulate agriculture water productivity $1 \%$ more than low urbanization ratio regions. The regional heterogeneity has therefore been verified.

4. Robustness test. To ensure the result's robustness, we employed two types of sensitivity test: the variable sensitivity test and sample sensitivity test.

The variable sensitivity tests were: first, urbanization wastewater emission was taken to replace the urban

Table 4 Variable descriptive statistics

\begin{tabular}{|c|c|c|c|c|c|c|}
\hline Variables & Unit & Observations & Mean & S.D & Min. & Max. \\
\hline Agriculture water productivity & $\mathrm{CNY} / \mathrm{m}^{3}$ & 210 & $-1.0600 \times \mathrm{e}^{-9}$ & 1 & -1.5200 & 4.4800 \\
\hline Urban wastewater treatment ratio & $\%$ & 210 & $-4.3900 \times \mathrm{e}^{-10}$ & 1 & -2.5000 & 1.8200 \\
\hline Urbanization ratio & $\%$ & 210 & $-3.7000 \times \mathrm{e}^{-9}$ & 1 & -3.0700 & 2.7600 \\
\hline The popularization rate of compulsory education & $\%$ & 210 & $9.8900 \times \mathrm{e}^{-10}$ & 1 & -3.0400 & 2.0800 \\
\hline Effective irrigation land & $\times 10^{3}$ ha & 210 & $-6.1900 \times \mathrm{e}^{-10}$ & 1 & -1.2200 & 2.2900 \\
\hline Agriculture investment in fixed asset & $\times 10^{8} \mathrm{CNY}$ & 210 & $-1.1100 \times \mathrm{e}^{-10}$ & 1 & -1.0300 & 4.6000 \\
\hline
\end{tabular}

Table 5 Primary test result

\begin{tabular}{|c|c|c|c|}
\hline & \multicolumn{3}{|c|}{ Agriculture water productivity } \\
\hline & Model 1 & Model 2 & Model 3 \\
\hline Urban wastewater treatment ratio & $0.2380 * * *(7.4000)$ & $0.2240 * * *(6.8700)$ & \\
\hline Urbanization ratio & & $0.0658(1.8400)$ & $0.1190 * * *(3.0400)$ \\
\hline The rural population compulsory education rate & $0.2160 * *(2.5100)$ & $0.1850 *(2.1300)$ & $0.1560(1.6000)$ \\
\hline Effective irrigation land & $-0.7040 * * *(-3.3700)$ & $-0.6830 * *(-3.2800)$ & $-0.5210 *(-2.2400)$ \\
\hline Agriculture investment in fixed asset & $0.3800 * * *(9.1200)$ & $0.3760 * * *(9.0800)$ & $0.5570 * * *(15.5300)$ \\
\hline Constant items & $-1.5600 \mathrm{e}^{-09}(-0.0000)$ & $-1.28 \mathrm{e}^{-09}(-0.0000)$ & $-1.03 \mathrm{e}^{-09}(-0.0000)$ \\
\hline$N$ Adjusted $R^{2}$ & $210(0.6853)$ & $210(0.6895)$ & $210(0.6080)$ \\
\hline
\end{tabular}


Table 6 Regression based on different urbanization ratio quantiles

\begin{tabular}{llll}
\hline & $10 \%$ quantiles & $50 \%$ quantiles & $90 \%$ quantiles \\
\hline Urban wastewater treatment ratio $\times$ low urbanization ratio & $0.2570^{* *}(3.2600)$ & $0.1640 * * *(4.4600)$ & $0.2260 * * *(6.8300)$ \\
Urban wastewater treatment ratio $\times$ high urbanization ratio & $0.2340^{* * *}(7.0600)$ & $0.3330^{* * *}(8.2300)$ & $0.3610^{* * *}(3.9000)$ \\
The popularization rate of compulsory education & $0.2200^{*}(2.5300)$ & $0.2760^{* *}(3.2600)$ & $0.2200^{*}(2.5700)$ \\
Effective irrigation land & $-0.7710^{* * *}(-3.2600)$ & $-0.8710^{* * *}(-4.2100)$ & $-0.7330^{* * *}(-3.5000)$ \\
Agriculture investment in fixed asset & $0.3820^{* * *}(9.0700)$ & $0.3900^{* * *(9.6800)}$ & $0.3880^{* * *(9.2600)}$ \\
Constant items & $0.0008(0.0500)$ & $-0.0232(-1.3200)$ & $-0.0106(-0.5700)$ \\
$N$ Adjusted $R^{2}$ & $210(0.6825)$ & $210(0.7063)$ & $210(0.6871)$ \\
\hline
\end{tabular}

wastewater treatment ratio to test urban wastewater's influence on agricultural water productivity. Second, all the primary control variables selected in chapter 2.2 were added into this model to weaken the endogeneity.

We employed several methods to undertake sensitivity tests. First, we excluded very high and low urban wastewater treatment ratio regions and only kept the medium-level ones. Second, in 2001 China won the bid to host the 2008 Olympic Games, from when on China invested in urban infrastructure to reduce pollution. But according to media reports, the city infrastructure's operation and maintenance deteriorated as the governance and supervision were not as strict as before. So we divided the sample into two time phases, samples from 2004 to 2007 and samples from 2008 to 2010 to test urban wastewater treatment's effect on agriculture water productivity in different phases under different policy circumstances.

According to the results, first, when the urban wastewater emission amount replaces the urban wastewater treatment ratio, the adjusted $R^{2}$ does not change prominently, but the urban wastewater emission amount's effect turns to be insignificant. Compared with the variable of urban wastewater emission amount, the urban wastewater treatment ratio reflects urban wastewater's influence on agriculture water productivity better.

Second, when all the control variables mentioned in chapter 2.2 were added into the model, the adjusted $R^{2}$ increased from 0.6895 to 0.7333 , which implies although several of those control variables failed to pass the correlation test, stationarity test and co-integration test, they can still explain agriculture water productivity's fluctuation to some extent. Urban wastewater treatment ratio's correlation coefficient decreases slightly, but is still positive at the 0.01 significance level.

Third, when the lowest five urban wastewater treatment ratio municipal provinces, Qinghai, Heilongjiang, Guizhou, Jilin and Hunan as well as the highest five urban wastewater treatment ratio municipal provinces, Yunan, Beijing, Shandong, Shanghai and Jiangsu were excluded from the sample, the urban wastewater treatment ratio's correlation coefficient decreased from 0.224 to 0.168 , but was still positive at the
0.01 significance level. That shows the sample size does not influence the model's robustness unduly.

Fourth, the sample was divided into two phases. In 2004-2007, the urban wastewater treatment ratio's correlation coefficient was 0.0681 , and the adjusted $R^{2}$ was 0.3623 , while in 2008-2010, the urban wastewater treatment ratio's correlation coefficient was 0.0671 , and the adjusted $R^{2}$ was 0.3862 . The former one was positive at the 0.01 significance level, but the latter one was insignificant. This implies that the urban wastewater treatment ratio's effect on agriculture water productivity is influenced by pollution control policy's implementation. These four robustness test models provided consistent results, meaning that the robustness test was passed.

\section{Conclusion and policy implications}

China's urbanization ratio has reached $50 \%$, which is recognized internationally as a peak water pollution crisis period. When the urbanization ratio is higher than $50 \%$, the water crisis can turn from being a quality crisis to being a quantity crisis. This is why China's water deterioration has frequently caused water pollution. Meanwhile, this is also critical period to renovate the water ecological environment (Qiu 2013). Therefore, in order to quantify China's water pollution effect on ecological growth, society development and environment protection it is urgent to increase the urban wastewater treatment ratio.

The results presented above show that the urban wastewater treatment ratio has prominent and positive effect on agriculture water productivity. Adding other control variables does not change the significance of this effect. When the government's environmental protection policy's implementation is more thorough, the impact turns out to be more effective. The finding provides substantial evidence for the strengthening of China's urban water environment management and is also instructive when formulating policies on the urban wastewater treatment ratio.

First, speeding up transitional influences on economic growth is the fundamental way to solve China's urban 
wastewater pollution. Urban wastewater emission reduction and water productivity increases are 'light green' sustainability development modes, while wastewater emission reduction is a 'deep green' way. In the past 30 years, rapid growth caused China to pay a high environmental price. Water pollution and low water endowment demonstrate that China no longer has sufficient water to sustain its extensive consumption pattern. That's why the government is trying to regulate the economic growth pattern, changing from a resource-driving pattern to an innovationdriven pattern, using macro-policies. It aims to achieve the goal of deeper-level sustainable water utilization.

Second, it is worth giving consideration to both economic growth and society's development. Economic growth and society development can have four kinds of combinations: economy grows and society develops, economy grows while society does not develop, economy does not grow and society does not develop, economy does not grow while economy develops. China is trying to achieve the goal of economy grows and society develops, which includes improving the ecological environment, and improving the city and country dual structure. The previous growth pattern was, arguably, biased toward economic growth while neglecting environment and society development, which potentially leads to unsustainable development. Now, it is time to adjust the former way. This strategy has been reflected in the government's recent policy changes, and in particular the decision of the CPC Central Committee which was announced in November 2013. That policy announced that environmental protection is an important indicator in evaluating China's sustainability.

Third, wastewater treatment construction and operation are specific strategies to reduce urban wastewater pollution. For natural monopoly goods like water, its provision and the wastewater treatment can utilize both state-owned enterprises and public-private participation. Thus, in low urbanization regions, encourage public participation, introduce social capital to take part in wastewater treatment fertilization construction which increasing government investment. In high urbanization cities, when relevant adequate wastewater treatment systems have been constructed, it's needed to establish and enable an evaluation system to evaluate wastewater treatment plants' operation. Public participation is also encouraged to supervise urban wastewater treatment operations.

Fourth, multiple effective strategies are needed to increase agricultural water productivity besides increasing city wastewater treatment ratios. The processes by which cities feed rural areas in return, and how industry compensates agriculture need to be more targeted. This requires putting investment into fields that can prompt resource conservation and have the most impact on agricultural productivity. The regression results of this paper show that agriculture investment in fixed asset as well as the rural population compulsory education rate has positive effects on promoting agricultural water productivity. Therefore, sustainable agriculture production would benefit from increasing inputs into these two fields.

Fifth, we establish a well-organized capital flow supervision and management system to support city support for rural areas. In 2011, the Central Document No. 1 stipulates $10 \%$ of the arable land transferring fee should be invested into agricultural water conservancy. But the execution did not work well in 2012-2014. In 2012, 200 trillion should have been invested into agricultural conservatory fields as there was 2000 trillion arable land transferring fee, but only 27 trillion was provided for agricultural conservancy which made the Central Document No. 1 less effective. In 2013, the water resource ministry and the finance ministry jointly issued the Agricultural Water Conservancy Fund Management from Arable Land Transfer Arranged by The Central Coordination Document to supervise each province's fund implementation. But in 2014, the Treasury and Department of Agriculture found some provinces did not put the Central Document No. 1 into practice well through investigation. This indicates that future policy should pay attention on how to improve the supervision and management system about city support for rural water conservatory.

Acknowledgements The research presented here was supported in part by a high-level university for state construction projects fund financed by Country Scholarship Council of China, Shanghai Philosophy and Social Science Youth Program (2016ECK001). We appreciate their support.

Open Access This article is distributed under the terms of the Creative Commons Attribution 4.0 International License (http://creativeco mmons.org/licenses/by/4.0/), which permits unrestricted use, distribution, and reproduction in any medium, provided you give appropriate credit to the original author(s) and the source, provide a link to the Creative Commons license, and indicate if changes were made.

\section{References}

Forrester JW (1971) World dynamics. Wright-Allen Press, Inc., Cambridge

Huang X, Shu Y (2010) Endogenous research on China's provincial trade opening and economy increase. Manag World 7:57-65

IWMI (2013) http://www.gwp.org/en/The-Challenge/The-Urgency-ofWater-Security/Urbanisation/

Knox JW, Kay MG, Weatherhead EK (2012) Water regulation, crop production, and agriculture water management-understanding farmer perspectives on irrigation efficiency. Agric Water Manag 108:3-8

Li J, Li H, Xie L (2012) Chinese agriculture pollution discharge potential, discharge efficiency and influential factors. J Agrotech Econ $6: 118-126$ 
Nickum JE (1998) Is China living on the water margin? Cambridge University Press 156:880-898

Qiu BX (2013) China's city water safety and countermeasure. City Dev Res 20(12):122-128

Rezadoost B, Allahyari MS (2014) Farmers' opinions regarding effective factors on optimum agricultural water management. J Saudi Soc Agric Sci 13(1):15-21

Shen D, Liu B (2008) Integrated urban and rural water affairs management reform in China. Phys Chem Earth 33(5):364-375

Shi RG, Liu FZ, Zhao YJ et al (2008) Research on safe utilization of reclaimed municipal wastewater in agriculture in China. Chin Agric Sci 41:2355-2361

Thomas A (2008) Agricultural irrigation demand under present and future climate scenarios in China. Global Planet Change 60(3-4):306-326

Tian YH, Zhu DJ, Wang HM et al (2013) Water footprint of China's Five major crops: 1978-2010. China's Popul Resour Environ 23(6):122-128

Tian YH, Ruth M, Zhu DJ (2017) Using the IPAT identity and decoupling analysis to estimate water footprint variations for five major food crops in China from 1978 to 2010. Environ Dev Sustain 19(6):2355-2375
Varis O, Vakkilainen P (2001) China's 8 challenges to water resources management in the first quarter of the 21st century. Geomorphology 41:93-104

Wang X (2007) Urban water resource sustainable exploration and utilization. Ph.D. Dissertation of Nankai University

Webber M, Barnett H, Finlayson B et al (2008) Pricing China's irrigation water. Glob Environ Change 18:617-625

Zhang Y, Jin XW (2009) It's not scientific to determine china's urbanization level by comparing industrialization ratio with urbanization ratio. Stat Meas 19:156-157

Zhang W, Zhang J (2010) Empirical study of agriculture outcome increase and its influential factors. Macroecon Study 7:59-63

Zhao XF, Li YQ (2009) Empirical analysis of Chinese agricultural influence factors based on panel data. Appl Stat Manag 28(1):128-134

Zhou YP, Huang GQ (2007) China's wastewater centralized processing: present and countermeasure. Resour Dev Mark 23(6):526-529

Publisher's Note Springer Nature remains neutral with regard to jurisdictional claims in published maps and institutional affiliations. 